\title{
BMJ Open Trainee doctors' experiences of learning and well-being while working in intensive care during the COVID-19 pandemic: a qualitative study using appreciative inquiry
}

To cite: Warren J, Plunkett E, Rudge J, et al. Trainee doctors' experiences of learning and well-being while working in intensive care during the COVID-19 pandemic: a qualitative study using appreciative inquiry. BMJ Open 2021;11:e049437. doi:10.1136/ bmjopen-2021-049437

- Prepublication history for this paper is available online. To view these files, please visit the journal online (http://dx.doi. org/10.1136/bmjopen-2021049437).

JW and EP are joint first authors.

Received 27 January 2021 Accepted 28 April 2021

Check for updates

(c) Author(s) (or their employer(s)) 2021. Re-use permitted under CC BY-NC. No commercial re-use. See rights and permissions. Published by BMJ.

${ }^{1}$ Anaesthesia and Critical Care Medicine, Queen Elizabeth Hospital Birmingham, Birmingham, UK

${ }^{2}$ Social Science Applied to Healthcare Improvement Research (SAPPHIRE) Group, Health Sciences, University of Leicester, Leicester, UK

Correspondence to

Dr Randeep Mullhi;

Randeep.Mullhi@uhb.nhs.uk

\section{ABSTRACT}

Objectives Concern about trainee work-related wellbeing has been raised in recent years and is the subject of several reviews, reports and research studies. This study aimed to understand the experiences of trainees working in a large intensive care unit during the first surge of the COVID-19 pandemic from an educational and operational perspective in order to highlight what worked and what could be improved.

Design A qualitative study using peer-to-peer semistructured interviews, developed using appreciative inquiry methodology, was conducted during July 2020. Responses were analysed using a thematic analysis technique.

Setting A large, tertiary intensive care unit in the UK. Participants All trainees in anaesthesia and intensive care working on the intensive care unit during the first surge were invited to participate.

Results Forty interviews were conducted and four overarching themes were identified. These were: feeling safe and supported; physical demands; the emotional burden of caring; and a sense of fulfilment, value and personal development. Positive aspects of the organisational response to the pandemic included communication, personal protective equipment supply, team working and well-being support. Suggestions for improvement focused on rest facilities, rota patterns and hierarchies, creating opportunities for reflection and ensuring continued educational and training opportunities despite operational demands.

Conclusions Trainees described opportunities for learning and fulfilment, as well as challenges, in working through a pandemic. Trainees described their needs and how well these were met during the pandemic. Ideas for improvement most frequently related to basic needs including safety and fatigue, but suggestions also related to supporting learning and development. The appreciative inquiry methodology of the project facilitated effective reflection on positive aspects of trainee experiences.

\section{INTRODUCTION}

Working in the COVID-19 pandemic has been an unprecedented experience for
Strengths and limitations of this study

- A large sample of available participants was interviewed, and data saturation was reached.

- The appreciative inquiry methodology encouraged reflection on strengths as well as areas for improvement.

- The interview process enabled reflective practice, which was felt to be positive by participants.

- The study was conducted in a single trust, and experiences may be different in different settings.

healthcare workers. The rapid spread of the pandemic necessitated expeditious changes to the delivery of healthcare in response to this novel disease with many unknowns. ${ }^{1}$ This can be illustrated by considering the changes made in the trust in which this study was conducted, a large teaching hospital in the Midlands, UK. At the peak of the first wave of the pandemic in April 2020, we had 98 patients with COVID-19 who required ventilation on our intensive care unit (ICU). Changes in our ICU included operational factors such as altered working patterns and hierarchical structure (figure 1A,B); logistical factors such as working in personal protective equipment (PPE) and clinical factors involving the development of new policies and procedures. ${ }^{23}$ Social distancing measures also impacted on the conduct of non-clinical work such as operational and educational meetings. ${ }^{45}$

Trainees have dual roles at work; to train in their chosen specialty while also being an essential part of the delivery of healthcare. As trainee anaesthetists and intensivists were at the forefront of responding to the pandemic, the necessary changes to their working pattern and environment in response to the 
A

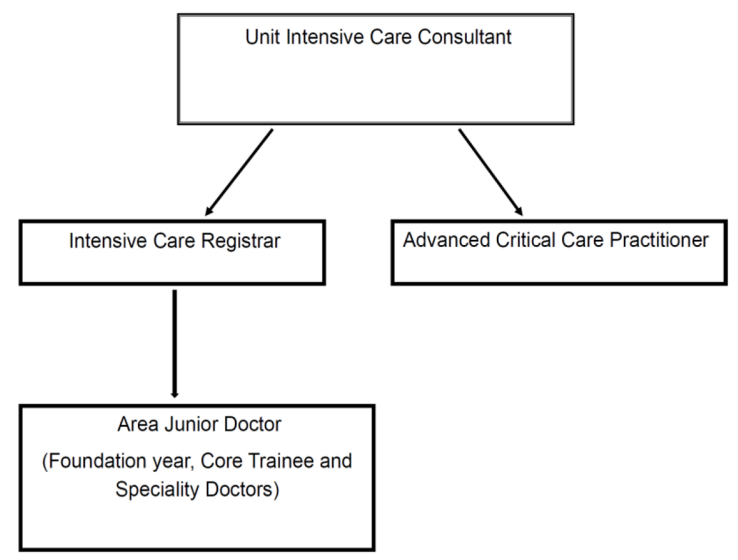

B

COVID-19 Critical Care Staffing Structure

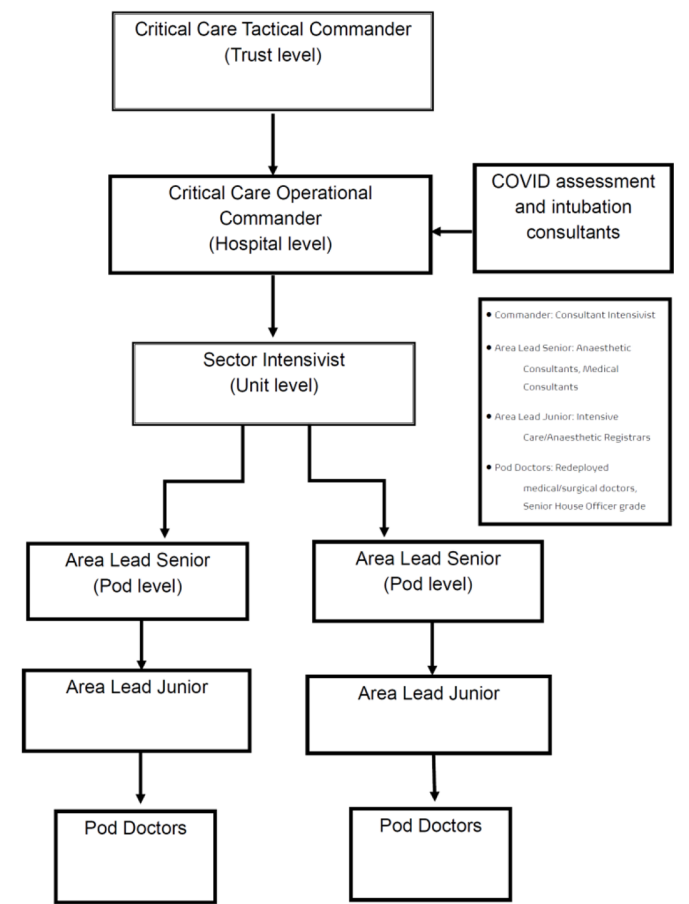

Figure 1 (A) Pre-COVID-19 intensive care unit staffing levels. (B) Intensive care unit staffing levels during the COVID-19 pandemic.

pandemic had the potential to impact on their roles, their experiences of learning and their well-being. ${ }^{45}$

Prior to the pandemic, concerns had already been raised about trainee work-related well-being. In 2017, the Royal College of Anaesthetists published a report into the welfare, morale and experiences of anaesthetists in training. ${ }^{6}$ The report covered numerous themes such as systems pressures, the burden of assessment and training, and the importance of adequate rest and catering facilities. A supportive culture was noted to be essential to nurture well-being. The report highlighted the impact of work on the mental health of anaesthetists in training, with $61 \%$ feeling that their job negatively affected their mental health and $19 \%$ reporting excessive levels of stress.

The 'SWeAT' study explored the mental health of anaesthetic trainees in the South West of the UK. The study identified factors enabling work satisfaction (patient contact, the privilege of enabling good patient outcomes and good support at home and work), along with the stressors of being an anaesthetic trainee (nonclinical workloads, the burden of training and changing societal expectations). ${ }^{7}$ The study provided suggestions for improvement of the working environment of trainees, including a need for increased awareness that doctors can struggle to cope, and that well-being support must be prioritised.

These issues are not unique to anaesthesia and intensive care, with recent national work being undertaken to improve the working lives and well-being of junior doctors. $^{89}$ The General Medical Council (GMC) now monitors the risk of burnout in both trainees and trainers as part of the National Training Survey and it has also commissioned a review into the well-being of junior doctors. $^{1011}$

The significant changes to working practices necessitated by the pandemic described above, occurred on this background of on-going concern relating to trainee well-being. The objective of our study was to explore the experiences of anaesthesia and intensive care trainees in relation to their learning and well-being in a single UK hospital during the first wave of the pandemic, in order to identify lessons for improvement.

Traditional approaches to improvement often focus on identification of problems to fix. An alternative method is to identify what works well and then build on this. Appreciative inquiry (AI), with its roots in positive psychology, aims to find solutions to individual and organisational change by considering strengths and possibilities. It encompasses a philosophy, guiding principles and practical tools for implementation. ${ }^{12}{ }^{13}$ Using this approach, we sought to understand trainee perceptions of the educational and operational aspects of their placement, and of their well-being during the pandemic. We aimed to gain insight into how to support the learning and resilience of trainees in the event of future pandemic surges.

\section{METHODS}

We conducted a qualitative study using semistructured interviews with foundation programme doctors and trainees in anaesthesia and intensive care medicine working within the ICU of our acute hospital trust. This 
Table 1 Topic guide for appreciative inquiry interviews

1. Thinking back to February before COVID-19 was an issue, what did you value most about your placement?

2. Did this change when we were moved onto the emergency COVID-19 rota? If so, how?

3. What are your strengths and how were they used during the COVID-19 surge?

4. What did you value most about the hospital response to the COVID-19 surge?

5. What stretched you during the COVID-19 surge? What factors helped you to manage?

6. What were your most valuable educational experiences during the COVID-19 surge?

7. If you had a magic wand and could have three wishes granted to improve trainee experience/working conditions if we experience a second COVID-19 surge, what would they be?

8. Do you have any ideas about how we could implement these ideas?

9. If willing, please would you share your grade and specialty?

10. Do you have any other comments?

design was used as we aimed to explore participants' experiences and perceptions. All eligible trainees were contacted via the trust email system and invited to contact the study team if they were interested in participating. A topic guide (see table 1) was used to structure the interviews, and was informed by pre-existing AI-based entrance and exit interview questionnaires developed by one of the authors (EP). ${ }^{14}$ The interview technique was similar to that used effectively in other healthcare settings. ${ }^{15}$

To enable trainees to speak as freely as possible, all interviews were conducted by trainee peers. The interviewers were familiar with AI methodology and supported by one author who has undertaken formal training in this approach (EP). Verbal consent was confirmed immediately prior to commencing the interview. Responses were anonymised and trainees were given the option to withhold their grade and specialty details if they wished. The interviews were not audio-recorded due to concerns that this might limit the depth of the responses. However, to reduce researcher bias, permission was sought from the interviewees to make verbatim, anonymised written notes.

Interviews were conducted face-to-face in the workplace or via video conferencing during the month of July 2020. Analysis was conducted alongside interviews, and themes were reviewed iteratively to assess the point at which data saturation had been reached-where no new codes or themes were identified from interviews. Any trainee felt to be struggling or requiring support, either when approached or during the interview process, was directed to our departmental well-being support services.

A thematic analysis approach was used by the interviewers to analyse the interview data. ${ }^{16}$ This involved open coding of a sample of verbatim interview transcripts by two researchers (JW and CT). Open codes were reviewed and combined into themes, drawing on Maslow's hierarchy of needs to inform the development of these themes. ${ }^{17} 18$ Data from all interviews were then collated on a spreadsheet according to theme. The validity of the findings was assessed through review and feedback by members of the team who were themselves members of the trainee workforce.

\section{Patient and public involvement}

There were no patients involved in this study.

\section{RESULTS}

A total of 40 semistructured interviews were conducted with trainees of different grades (see figure 2). All trainees were comfortable providing their grade and specialty details despite being given the option to withhold this information.

The majority of respondents were supportive and accepting of the changes to their working pattern, workload and environment. Analysis of the coded responses revealed four overarching themes that described trainee experiences of well-being during the pandemic: feeling safe; physical demands; emotional burden and sense of fulfilment. There were more than 100 suggestions for improvement mentioned, in many cases accompanied by ideas for implementation. These suggestions are presented in table 2, subdivided according to grade of interviewee and presented in descending order of frequency.

\section{Feeling safe and supported}

The pandemic caused concerns for trainees in terms of feeling safe and supported in their role. Proactive leadership, induction and support when redeployed and safe staffing levels were seen as very important to support wellbeing. Trust in the senior staff within ICU and anaesthesia helped trainees feel they would be supported and enabled to do their job safely. Perceptions of the organisational response to the pandemic as 'proactive not reactive', 'wellthought through and planned, always one step ahead' were important in their sense of safety as employees. One trainee commented on the 'great demonstration of leadership when under pressure'.

Trainees appreciated both $24 / 7$ consultant presence and also the numbers of doctors who were redeployed to the ICU. Medical staff levels were generally felt to be good, with comments such as '(we) never felt shortstaffed'. Others mentioned that redeployed staff were quick to learn the ropes and that things were 'as safe as possible'. Senior trainees reported being comfortable in the ICU environment which gave the junior trainees confidence. The pausing of elective work was highlighted as beneficial, giving trainees 'time to breathe' and undertake essential training for the pandemic.

In terms of safety, trainees were concerned about exposure to COVID-19 and respondents, therefore, 


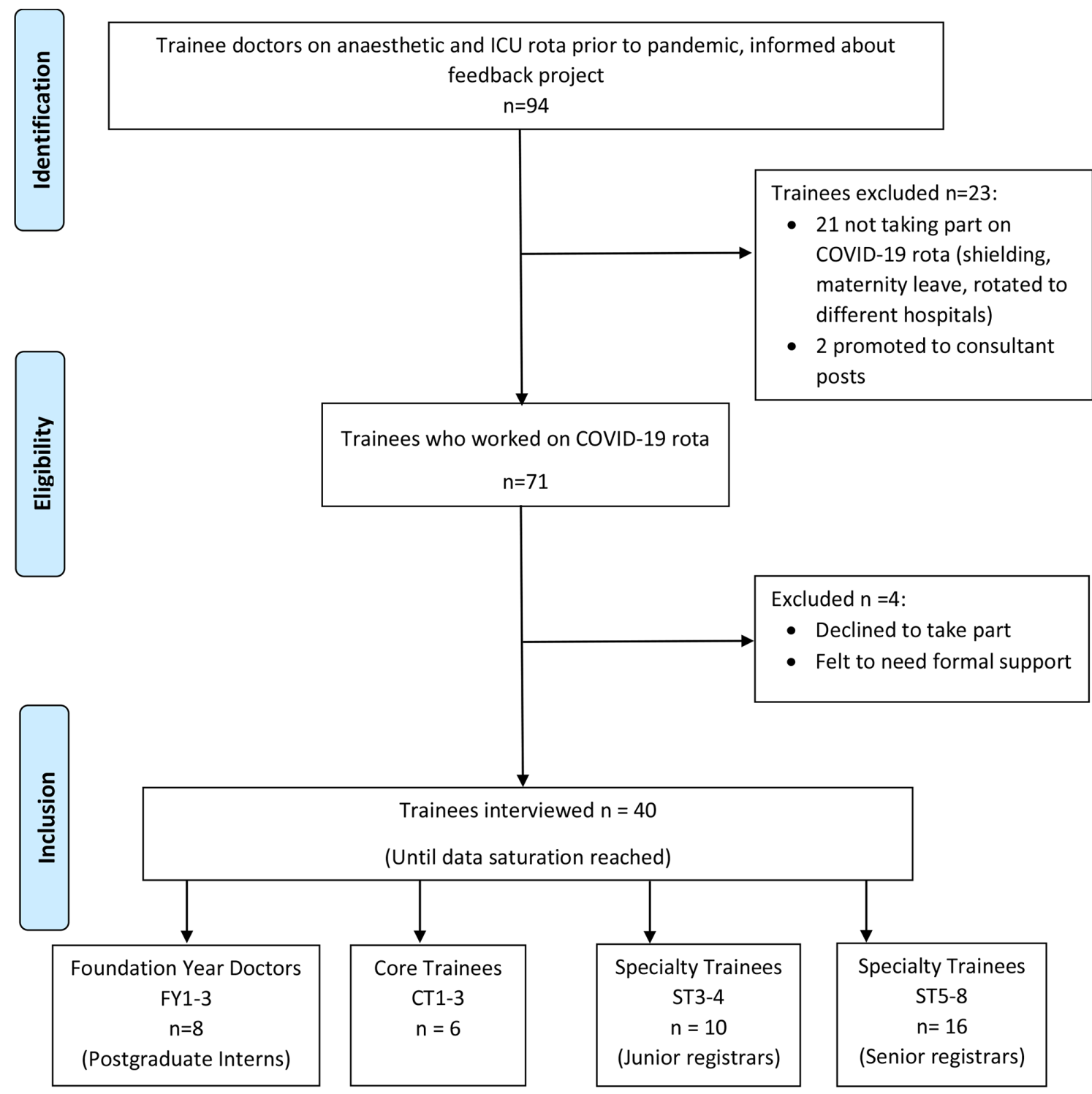

Figure 2 Flow diagram of participant numbers. ICU, intensive care unit.

appreciated the organisational response in ensuring sufficient stock of PPE. Organisational efforts to protect employee well-being needed to be balanced against the risk of exposure to COVID-19. For example, the difficulty of socially distancing in rest areas was noted with comments such as, '(the wellbeing room) kept us sane but was wholly inadequate for keeping us safe': Improvement in facilities were suggested to improve safety.

\section{Physical demands}

The majority of respondents found the emergency COVID-19 rota challenging, with comments such as 'it was very stressful over a prolonged period'; 'intense and not sustainable'; 'poor for physical and mental health and nights were crippling'. Only one trainee reported liking the rota. High levels of demand, a lack of control and, for some trainees, a lack of a consistent team of colleagues, all impacted negatively on well-being. The long hours in PPE were physically demanding, with breaks from PPE being inconsistent, leading to airway-trained respondents reporting lengthy periods in PPE. Trainees accepted that they had a duty to respond to organisational needs in this time of crisis and made positive suggestions for ways to reduce the impact. These included alterations to the rota, such as increased planning for breaks while allowing continuity of patient care.

Trainees were highly appreciative of organisational efforts to support them with facilities such as food, free parking and rest facilities. This helped them cope with long hours and variable shifts, as one trainee commented, 'I would like the free parking to continue, although I didn't make use of it, I could see it helped others enormously'. The provision of food also promoted well-being by providing an opportunity for socialising and bonding with colleagues. 'Food brought joy and got people together'.

One-third of trainees suggested the provision of adequate rest facilities as critical for supporting well-being. 
Table 2 Topics of answers related to 'three wishe... to improve trainee experience and working conditions' with illustrative verbatim comments

\begin{tabular}{|c|c|c|}
\hline & $\begin{array}{l}\text { Topics of comments with examples (no. of } \\
\text { comments) }\end{array}$ & $\begin{array}{l}\text { Suggestions for implementation (no. of } \\
\text { comments) }\end{array}$ \\
\hline $\begin{array}{l}\text { Foundation } \\
\text { programme (FP) } \\
\text { doctors }\end{array}$ & $\begin{array}{l}\text { Rota design ( } n=6) \text { : 'Rationalise the need to put } \\
\text { everyone on an emergency rota'; 'less nights and } \\
\text { less intensity'; 'build more leave into the rota' } \\
\text { Organisation of redeployment/staffing }(n=5) \text { : 'more } \\
\text { nurses'; 'set structure of working' } \\
\text { Education and training ( } n=4) \text { : 'increased ability to } \\
\text { do procedures'; 'formal teaching'; 'teaching ward } \\
\text { rounds needed' } \\
\text { Team working ( } n=3) \text { : 'Keep people in teams who } \\
\text { they work with regularly'; 'more continuity between } \\
\text { teams, consultants changed (too frequently)' } \\
\text { PPE ( } n=2) \text { : 'less time in PPE'; Environment ( } n=1) \text {; } \\
\text { 'more physical space'. } \\
\text { Clinical care }(n=1): \text { 'proning - how to reduce harm' } \\
\text { (Total } n=22 \text { ) }\end{array}$ & $\begin{array}{l}\text { Rota design }(n=3) \text { : 'Standby teams'; 'self- } \\
\text { rostering'; 'keep areas with consultant group' } \\
\text { Teaching }(n=1) \text { : 'Teaching ward rounds' } \\
\text { Proning }(n=1) \text { : 'QIP for proning' } \\
\text { PPE }(n=1) \text { : 'more variety' } \\
\text { (Total } n=6)\end{array}$ \\
\hline
\end{tabular}


Table 2 Continued

Topics of comments with examples (no. of comments)
Suggestions for implementation (no. of comments)
Senior registrar Rota design $(n=15)$ : 'no imposed rota changes'; (ST5-8) 'more days off'; 'parity and fairness with COVID-19 ICU allocation'; 'if consultants are not on an emergency rota nor should trainees be on one'.

- Leadership and management $(n=9)$ : 'involve anaesthetic trainees in the assessment and intubation of patients'; 'consider stepping senior registrars to leadership roles'; 'allow senior trainees to have a level of autonomy, for example, make them area leads'.

- Rest and refreshment facilities $(n=5)$; preparedness and PPE $(n=5)$

- Communication and debriefing $(n=5)$ : 'better communication regarding stepping us up or down, honesty and clarity for doing so'; 'one location for important at a glance changes'; 'improve command structure and handover process'.

- Education and training needs $(n=5)$ : 'rotate us around different teams'; 'involve senior trainees in the bunker meetings'; 'time back for missed training - I want to get more experience and ensure I'm appropriately trained.'

- Team-working/support $(\mathrm{n}=3)$

(Total $\mathrm{n}=47$ )
- Leadership experience $(n=3)$ : 'make senior trainees area leads'; 'get senior trainees in designated supportive roles to help junior trainees'.

- Teaching $(\mathrm{n}=3)$ : 'capitalise on the educational opportunities at hand (respiratory, renal, heart failure)'; encourage '(redeployed) specialists provide formal teaching on these topics'

- Role allocation $(\mathrm{n}=2)$

- Rota design $(\mathrm{n}=2)$ (Total $\mathrm{n}=10$ )

\section{Emotional burden}

The emotional burden of the pandemic was clear with comments such as, 'I felt powerless with patients deteriorating and how many patients were dying', 'a lot of young people died. I don't think I'll ever be able to put that out of my mind'. Respondents also found it hard observing the nursing staff being stretched and struggling. 'I would use all my three wishes for the nurses, it was bad for us but ten times worse for them', 'it was very stressful as I couldn't reassure them (the nurses)'.

The absence of visitors and contact with relatives was a double-edged sword. Some trainees found it helped them 'remain remote and cope with the sheer number of abrupt deaths', others described heart-breaking phone calls with one commenting, 'I can't believe I cried in front of a consultant when I put down the phone'.

Due to the workload, some junior trainees reported missing opportunities to observe communication around decision making for significant events like withdrawal of life-sustaining therapy. This led to emotional distress with one junior trainee noting that, 'the decisions were not always well explained (to the trainees)'.

Overall the emotional burden was felt, by trainees, to impact significantly on their well-being.

Social support from colleagues was important in helping trainees deal with the emotional impact. The benefits of the same teams working together were highlighted with the majority mentioning this during their interviews. 'Close team', 'camaraderie', 'working with the same group of people' were common factors that helped trainees manage. In addition, trainees who lived alone or were living apart from their families found the 'lack of human contact' during their time away from work immensely difficult. Working as part of a team was particularly invaluable for them. Trainees who were moved to different teams had a challenging time making comments such as, 'It was like starting in a new hospital every shift'.

The usual methods of both formal and informal debriefing were missed, particularly by the more senior trainees involved with incidents, and they suggested that formal debriefing sessions would be valuable: 'I think it is important to learn from cases and experience, I wanted this in a more formal capacity similar to the donning and doffing training'. Many respondents wished that teaching sessions had continued, not just because of the educational aspect, but because of the social support; 'I missed formal teaching and the contact with a senior and a focused coming together of a speciality group'.

Departmental well-being initiatives were seen as playing a critical role in supporting trainees to cope with the emotional burden of the crisis. Respondents who had interacted with the peer support team, reported this to be an essential resource; 'someone identified me as struggling and I was grateful for the support they offered me, as I would not have sought help myself and just tried to cope'. Another respondent reported using skills that had 
been previously acquired by working with the well-being team to help them with self-care.

Improvements to address psychological needs were mentioned least frequently in the suggestions for improvements, but included recognition of the need to optimise team working and improvements to debriefing.

\section{Sense of fulfilment, value and personal development}

Achieving a sense of fulfilment, value and personal development was critical to trainee well-being during the crisis. A minority of interviewees from all grades felt their strengths were 'disappointingly under-utilised' or that they were 'unable to contribute fully'; a few described working during the pandemic as monotonous or 'educationally devoid'. However, most trainees gave examples of valuable learning experiences, with several recognising the educational value of 'encountering a disease for which there was no textbook treatment'. Trainees in all groups mentioned using their skills to support other staff in the multidisciplinary team, and some described teaching redeployed staff; this was seen by trainees as rewarding and fulfilling. 'I'm an educator so [I] saw it as an opportunity for people to learn what we do in ICU'.

The most junior trainees suggested that the experience helped them consolidate the non-technical skills that they had already started to develop. They also valued gaining a clearer grasp on the management of organ failure, and gaining general experience in the ICU.

Junior registrars reported experiences of personal and professional development through learning to solve clinical problems and work in new ways: 'I learned about coping with uncertainty', 'I learnt organisational stuff like resource and team management' and 'I enjoyed making independent decisions, it helped me grow and step up'.

The significant change to working practices seemed to have a more negative impact on senior registrars; 'I didn't feel mentally challenged which left me feeling very despondent'. Practical tasks like placement of lines, patient assessment and intubation were delegated to specific teams, leaving many trainees feeling demoralised. Comments were made such as; ' (protocolisation) stripped us of all autonomy; I just felt like a number in a corporate machine'. Some, however, described how the experience had enabled them to gain additional non-technical skills such as leadership and team management.

The suggestions to improve trainees' feeling of fulfilment, value and personal development included reinstating educational meetings and teaching ward rounds, with time taken to reflect on cases they had been involved with. There was also a desire to retain undertaking practical skills, possibly as part of the procedure teams, in the future.

\section{DISCUSSION}

Trainees described the significant impact of the pandemic on their working lives and well-being. Interviews were designed to highlight the positive aspects of adaptations to their working practice and to identify potential improvements to further support trainee wellbeing. Four overarching themes were identified: feeling safe and supported (preparedness, PPE and leadership), physical needs (working patterns, rest facilities, food and parking); coping with the emotional burden (psychological distress of caring, and the value of team-working, debrief and support) and self-fulfilment (feeling useful, education and training opportunities).

These themes describe the positive and negative aspect of working during the pandemic and can be seen as aligning with Maslow's hierarchy of human needs: basic needs (physiological and safety), psychological needs (belonging and self-esteem) and self-fulfilment (self-actualisation). ${ }^{17} 18$ All elements of Maslow's hierarchy were referenced in both the responses related to working during the pandemic and the suggestions for improvement. For each grade of respondent, the most frequent suggestions for improvement were around addressing basic needs (physiological and safety) such as through improved rota patterns and rest facilities; fewer suggestions were made that related to higher needs (see figure 3).

\section{Lessons for the future/recommendations for practice}

Our findings can be related to an existing framework, that was designed to inform interventions to address burnout .${ }^{19}$ This involves five levels of interventions: starting with basic needs for physical and mental health, then safety (for physicians and patients) before moving onto higher order variables such as respect, appreciation and contributing to the fullness of ones' potential. Based on the findings from this study, we identify key lessons for supporting trainee well-being and learning for the future:

1. Maintain the focus on improving rest facilities and rest areas. The provision of rest facilities is increasingly recognised as important for patient and trainee safety. ${ }^{19}$ In our trust, this was managed during the first surge by office space being given up to provide a well-being room (similar to the 'wobble rooms' in other units) ${ }^{20}$ and the purchase of an additional sofa bed. Despite these changes, rest-facilities were one of the most common wishes for improvement. These facilities need to be organised to avoid exposing staff to greater risk of infection.

2. Minimise the need for long shifts. Several trainees mentioned shift length as being challenging and having a balance of shorter shifts was highlighted as important for improving rota patterns. Research suggests that the risk of error increases with time on shift and Health and Safety Executive guidance highlights the importance of access to breaks and this is therefore both a staff and patient safety intervention. ${ }^{21} 22$

3. Create teams that work together regularly. Those who worked within the same team regularly described benefits, including social support and psychological safety. This has been recognised previously in documents describing team working both from within and outside 

Self-actualisation needs:
Skills utilisation and
development
$22 \%$
- education
- training
- leadership /
management
skills

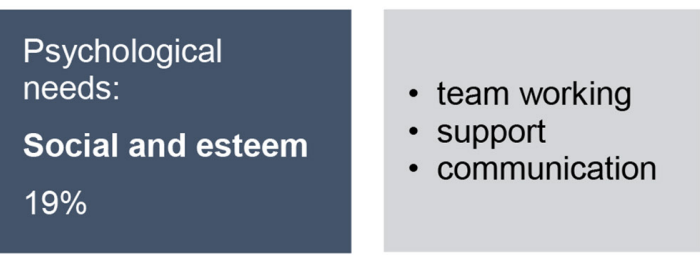

\section{Basic needs: \\ Physiological and safety}

$59 \%$

Figure 3 Frequency of suggestions for improvement according to Maslow's hierarchy of needs (dark grey box=hierarchy, with box size proportional to frequency of theme; light grey box=examples of topics within the theme). PPE, personal protective equipment.

healthcare. ${ }^{23-25}$ Conversely, those who worked with different teams reported struggling to a greater extent with the emotional burden of the pandemic. The benefits of working within coherent team structures to reduce physician burnout have been well described. ${ }^{26}$

4. Prioritise reflection and debrief. The emotional side of working during the pandemic was mentioned frequently, despite not being asked about directly. The benefits of setting up interventions for well-being, including peer support services, were apparent from the trainees' responses. Structured forums where staff from multidisciplinary backgrounds come together to discuss the emotional and social aspects of working in healthcare are well recognised in the literature, and our findings support the need to enable reflection and debriefing after stressful events. ${ }^{27-29}$

5. Factor in training opportunities when making changes to services. Our results suggest that the break from performing practical procedures during the pandemic impacted on both the trainees' perception of their education and also their sense of purpose at work. Competence is one of the three factors mentioned in the GMC's report 'Caring for Doctors, Caring for Patients' and is defined as: 'the need to experience effectiveness and deliver valued outcomes, such as highquality care'. ${ }^{11}$ Our findings are strongly supportive of the conclusions of this report. Many respondents found unexpected opportunities for learning and personal development. However, those who felt they were unable to achieve their full potential reported disillusionment with their work. This had a strongly negative impact on their well-being.
These suggestions are not necessarily surprising, but given that the National Health Service has not faced a pandemic previously, formally acknowledging these factors is important. Many of these factors are similar to those proposed by the Faculty of Medical Leadership and Management to improve the working lives of junior doctors. ${ }^{9}$ It is likely that they are also the factors needed to create a positive work environment, even in nonpandemic times.

\section{Limitations and strengths}

Accuracy of capturing responses could have been improved by recording the interviews or having a second interviewer present. It was felt that recording might affect the willingness of participants to speak freely and that social distancing would make the use of multiple interviewers difficult. However, all three interviewers were involved in data analysis, in order to improve reliability of data analysis.

Not everyone working on the COVID-19 rota was interviewed and also trainees who were struggling the most were excluded, which may have introduced a source of bias. However, more than half of the trainee workforce was included, with representation from all grades, and the interviewers unanimously agreed that data saturation had been reached after these interviews. All the issues highlighted were raised by more than one trainee. Therefore, we believe our findings to be representative of the trainee experience in our unit. The study was conducted in a single trust, and experiences may be different in different settings. 
The strengths of our study lie in the methodology applied. The interviews enabled reflection, which is well recognised for professional development, is vital to personal well-being and forms an essential element of GMC good medical practice. ${ }^{30}$ The interview structure provided a 'safe' space for trainees to reflect with a colleague. This gave an opportunity for trainees to gain a deeper understanding of situations that had been encountered. The use of an AI approach allowed the exploration of positive experiences and a focus on solutions, as opposed to just describing problems.

The importance of deliberative reflective practice to enable new perspectives and intentions for change has been well recognised previously. ${ }^{31-33}$ Learning positive lessons from reflection has significant value for organisational improvement. ${ }^{34}$ This project was supported by the trust and the feedback from this study has been used locally to inform organisational change. ${ }^{235}$

For the interviewers, this was an unequivocally constructive project to be involved with both in terms of the feedback attained and the ability to provide peers with the time to reflect on their experiences.

Future work should involve re-evaluation of trainee perceptions after implementation of the changes suggested, with the methodology embedded as part of routine feedback of trainee experience. Participant's opinion of the interview process and whether this impacted on their perception of their role would also be interesting to study.

\section{In conclusion}

Responding to the pandemic has tested the resilience of healthcare systems globally. Trainee doctors have been at the forefront of the response, especially those working in intensive care. This project was designed to understand their experiences of well-being and learning, acknowledge factors that worked well and identify positive suggestions for supporting trainee well-being during a pandemic. It has also facilitated peer-to-peer reflection, a positive process in itself. It is our aspiration that this methodology becomes part of routine practice to constantly improve trainee experience.

\section{Twitter Jennifer Warren @drjen_w}

\section{Acknowledgements We wish to acknowledge the doctors at Queen} Elizabeth Hospital Birmingham (part of University Hospitals Birmingham NHS Foundation Trust) who took part in the interviews, as well as the countless other staff members who worked tirelessly during the pandemic.We also wish to acknowledge the support of the West Midlands Patient Safety Collaborative and West Midlands Academic Health Science Network with the Learning from Excellence programme and Appreciative Inquiry training, which facilitated the methodology of this project.

Contributors JW, JR and CS interviewed the trainees and analysed the data. JW, $E P, J R, C S, T T$ and RM drafted the article. CT contributed to analysis and critical revision of the article. All authors gave approval of the final version.

Funding The authors have not declared a specific grant for this research from any funding agency in the public, commercial or not-for-profit sectors.

Competing interests None declared.
Patient and public involvement Patients and/or the public were involved in the design, or conduct, or reporting, or dissemination plans of this research. Refer to the Methods section for further details.

Patient consent for publication Not required.

Ethics approval Approval to conduct the study was obtained on 11 July 2020 from the Non-HRA Data Subgroup of the COVID-19 Research Assessment and Prioritisation Group of University Hospitals Birmingham NHS Foundation Trust (Study approval number COV141).

Provenance and peer review Not commissioned; externally peer reviewed.

Data availability statement Study data can be provided upon suitable request to the corresponding author.

Open access This is an open access article distributed in accordance with the Creative Commons Attribution Non Commercial (CC BY-NC 4.0) license, which permits others to distribute, remix, adapt, build upon this work non-commercially, and license their derivative works on different terms, provided the original work is properly cited, appropriate credit is given, any changes made indicated, and the use is non-commercial. See: http://creativecommons.org/licenses/by-nc/4.0/.

ORCID iDs

Tomasz Torlinski http://orcid.org/0000-0003-2255-5317

Randeep Mullhi http://orcid.org/0000-0002-2387-7126

\section{REFERENCES}

1 ICM \& Anaesthesia - Covid19. Information, guidance and resources supporting the understanding and management of coronavirus (COVID-19). Available: https://icmanaesthesiacovid-19.org/crossskill-training-for-pandemic-covid-19 [Accessed 15 Dec 2020].

2 Oakley C, Pascoe C, Balthazor D, et al. Assembly line ICU: what the long shops taught us about managing surge capacity for COVID-19. BMJ Open Qual 2020;9:e001117.

3 NHS England. Clinical guide for anaesthesia service reorganisation during the coronavirus pandemic. Available: https://www.england. nhs.uk/coronavirus/wp-content/uploads/sites/52/2020/03/Specialtyguide_Critical-care-and-anaesthesia-service-reorganisation_V1_17March.pdf [Accessed 5 Dec 2020].

4 Torlinski T, Kaur Mullhi R, Parekh D, et al. Postgraduate education and specialty training in anaesthesia and intensive care medicine during the COVID-19 pandemic: experience from a large teaching hospital in the United Kingdom. Anaesthesiol Intensive Ther 2020;52:434-7.

5 Sneyd JR, Mathoulin SE, O'Sullivan EP, et al. Impact of the COVID-19 pandemic on anaesthesia trainees and their training. $\mathrm{Br} \mathrm{J}$ Anaesth 2020;125:450-5.

6 Royal College of Anaesthetists. A report on the welfare, morale and experiences of anaesthetists in training: the need to listen, 2017. Available: https://rcoa.ac.uk/sites/default/files/documents/2020-09/ Welfare-Morale2017.pdf [Accessed 22 Dec 2020].

7 Looseley A, Wainwright E, Cook TM, et al. Stress, burnout, depression and work satisfaction among UK anaesthetic trainees; a quantitative analysis of the satisfaction and wellbeing in anaesthetic training study. Anaesthesia 2019;74:1231-9.

8 Health Education England. NHS Staff and Learners' Mental Wellbeing Commission, 2019. Available: https://www.hee.nhs.uk/our-work/ mental-wellbeing-report [Accessed 22 Dec 2020].

9 NHS Improvement:. Eight high impact actions to improve the working environment for 8 junior doctors. Available: https://improvement. nhs.uk/documents/1884/NHS-8-high-impacts-A4v5Bm_with_ stickynotes_5_7dglFbL.pdf [Accessed 15 Dec 2020].

10 General Medical Council. National training survey report 2020. GMC Council 180107 0, 2020. Available: https://www.gmc-uk.org/

11 General Medical Council. Caring for doctors, caring for patients, 2019. Available: https://www.gmc-uk.org/-/media/documents/caringfor-doctors-caring-for-patients_pdf-80706341.pdf [Accessed 15 Dec 2020].

12 Quinney S, Slack T. Reflections. realising the power of Appreciative inquiry, 2017. https://appreciatingpeople.co.uk/ai-essentials/ reflections-journal/

13 Cooperrider DL, Whitney D. Appreciative inquiry: a positive revolution in change. Brett-Koehler Publishers Inc, 2005.

14 Learning from excellence. A call to learn from what goes well in healthcare. exit and entrance interviews. Available: https://learning fromexcellence.com/entrance-and-exit-interviews/ [Accessed $15 \mathrm{Dec}$ 2020]. 
15 Turner C, Lee-Shrewsbury V, Hill N. Exit interviews for junior DRSwhat can we learn? the POPE-I project. Emergency Medicine Journal 2016;33:930.1-930.

16 Braun V, Clarke V. Using thematic analysis in psychology. Qual Res Psychol 2006;3:77-101.

17 Maslow AH. A theory of human motivation. Psychol Rev 1943;50:370-96.

18 Hale AJ, Ricotta DN, Freed J, et al. Adapting Maslow's hierarchy of needs as a framework for resident wellness. Teach Learn Med 2019;31:109-18.

19 Association of Anaesthetists. Fatigue education resources. Available: https://anaesthetists.org/Home/Wellbeing-support/Fatigue/-FightFatigue-download-our-information-pack [Accessed 15 Dec 2020].

20 BBC News. Covid: NHS staff helped through crisis by 'wobble room., 2020. Available: https://www.bbc.co.uk/news/health-54877437 [Accessed 15 Dec 2020].

21 Folkard S, Tucker P. Shift work, safety and productivity. Occup Med 2003;53:95-101.

22 HMSO. Health and safety executive health and safety at work etc; act. London, UK: HMSO, 1974.

23 Health and Safety Executive. Managing shift work. Health and safety guidance. HSG 256, 2006. Available: http://www.hse.gov.uk/pUbns/ priced/hsg256.pdf [Accessed 15 Dec 2020].

24 Künzle B, Zala-Mezö E, Wacker J, et al. Leadership in anaesthesia teams: the most effective leadership is shared. Qual Saf Health Care 2010;19:e46.

25 Wacker J, Kolbe M. Leadership and teamwork in anesthesia making use of human factors to improve clinical performance. Trends in Anaesthesia and Critical Care 2014;4:200-5.

26 searchenginewatch.com. Google's five key success factors for effective teams (searchenginewatch.com). Available: https://www. searchenginewatch.com/2015/11/20/googles-five-key-successfactors-for-effective-teams [Accessed 15 Dec 2020]
27 Willard-Grace R, Hessler D, Rogers E, et al. Team structure and culture are associated with lower burnout in primary care. J Am Board Fam Med 2014;27:229-38.

28 The Point of Care Foundation. Schwartz rounds. Available: https:// www.pointofcarefoundation.org.uk/our-work/schwartz-rounds/ [Accessed 15 Dec 2020].

29 Maben J, Taylor C, Dawson J, et al. A realist informed mixedmethods evaluation of Schwartz center Rounds ${ }^{\circledR}$ in England. Health Serv Deliv Res 2018;6:1-260.

30 General Medical Council. The reflective practitioner - guidance for doctors and medical students. Available: https://www.gmc-uk.org/ education/standards-guidance-and-curricula/guidance/reflectivepractice/the-reflective-practitioner-guidance-for-doctors-andmedical-students [Accessed 15 Dec 2020].

31 Schon D. The reflective practitioner: how professionals think in action. New York, NY: Basic Books, 1983.

32 Brookes O, Brown C, Tarrant C, et al. Patient experience and reflective learning (pearl): a mixed methods protocol for staff insight development in acute and intensive care medicine in the UK. BMJ Open 2019;9:e030679.

33 Bion J, Brookes O, Brown C. A framework and toolkit of interventions to enhance reflective learning among health-care professionals: the pearl mixed-methods study. Southampton UK: NIHR Journals Library, 2020.

34 Zhou AY, Panagioti M, Esmail A, et al. Factors associated with burnout and stress in trainee physicians: a systematic review and meta-analysis. JAMA Netw Open 2020;3:e2013761.

35 Torliński T, Rakasz L, Wysota B, et al. An interdisciplinary approach to the management of critically ill patients during covid-19 pandemic; an experience of a university hospital in England. Wiad Lek 2020;73:1576-9. 